\title{
Association between pregnancy induced hypertension and maternal thyroid stimulating hormone levels - a hospital based observational case control study
}

\author{
Mahadevi Savanur, Anubha Kataria, Gauri Prabhu, Nitin Sutariya \\ Corresponding author: Dr. Mahadevi Savanur, Assistant Professor, Department of Obstetrics and \\ Gynaecology, JNMC, KAHER, Belgavi, Karnataka, India; Email : drdevim30@gmail.com
}

Distributed under Attribution-Non Commercial - Share Alike 4.0 International (CC BY-NC-SA 4.0)

\begin{abstract}
Background: With rise in incidence of hypertensive disorders of pregnancy especially pre -eclampsia, there is a need to study its association with other comorbid conditions like thyroid disorder which may have common pathophysiology. Objective: The following case control study was done to know the association between pregnancy induced hypertension and serum thyroid stimulating hormone (TSH) level. Methodology: This case control study was carried out at tertiary care hospital from June 2018 to December 2018 wherein we compared mean TSH level among hypertensive pregnant women (case) and normotensive pregnant women (control) in third trimester. We also further analysed the differences of mean TSH level within hypertensive group based on severity. The total sample size consisted of 300 cases and 300 matched controls. Results: Mean serum TSH level was found significantly higher in the hypertensive (case) group i.e (2.81 \pm 2.08$)$ as compared to the normotensive (control) group i.e $(2.32 \pm 1.24)$ with pvalue 0.0006 . The association between pre-eclampsia and hypothyroidism was seen by odds ratio of 1.87 (CI=1.06 3.27) for patients with severe pre-eclampsia, $1.41(\mathrm{CI}=0.78-2.55)$ for patients with non severe pre-eclampsia and1.24 (CI $=0.66-2.33$ ) for patients with gestational hypertension in comparison to the normotensive patients. Mean serum albumin was significantly lower in cases (3.22 \pm 0.43$)$ as compared to control groups (3.30 \pm 0.38$)$ with pvalue 0.0122 . However the correlation coefficient for the entire study population was $(-0.0532)$ between serum albumin and serum TSH, which suggests both values were independent of each other. Serum uric acid was significantly higher in cases as compared to controls $(\mathrm{p}<0.0001)$. Conclusion: Biochemical hypothyroidism in pregnancy is associated with pre-eclampsia especially with severe pre-eclampsia. However Serum TSH values need to be adjusted to the population and hospital for cut offs for reliable diagnosis.
\end{abstract}

Keywords: Hypothyroidism, preeclampsia, thyroid stimulating hormone, serum TSH.

Thyroid hormone plays an important function of maintaining homeostasis. However its role becomes critical in pregnancy and can severely affect both the maternal and fetal outcomes ${ }^{1}$. Maternal thyroid gland physiology undergoes various changes in pregnancy. Due to similarity to nonspecific symptoms of pregnancy, diagnosis of thyroid dysfunction becomes clinically difficult in pregnancy ${ }^{2}$. The assessment of thyroid stimulating hormone (TSH) levels to detect hypothyroidism in pregnancy has become a routine outpatient procedure as a part of antenatal care. ${ }^{3}$ Various studies done in the west have estimated the prevalence of hypothyroidism in pregnancy to be $2.5 \%^{2,4}$. However studies in Indian population have shown a much higher prevalence of $3.69 \%^{5}, 4.8 \%^{6}, 13.3 \%^{7}, 14.3 \%^{8}$.

Women with pregnancy induced hypertension have a greater propensity to develop biochemical hypothyroidism during pregnancy or even in later life ${ }^{9}$. Many mechanisms have been postulated in earlier studies for this. Maternal serum concentrations of total thyroxine $\left(\mathrm{TT}_{4}\right)$ and total triiodothyronine $\left(\mathrm{TT}_{3}\right)$ were significantly reduced with a

Received: $1^{\text {st }}$ December 2020, Peer review completed: $28^{\text {th }}$ February 2021, Accepted: $7^{\text {th }}$ March 2021.

Savanur M, Kataria A, Prabhu G, Sutariya N. Association between pregnancy induced hypertension and maternal thyroid stimulating hormone levels - a hospital based observational case control study. The New Indian Journal of OBGYN. 2022; 8(2): 227 - 32. 
correlation of thyroxine-binding globulin, total thyroxine $\left(\mathrm{TT}_{4}\right)$, total triiodothyronine $\left(\mathrm{TT}_{3}\right)$ levels with newborn birth weights in patients with pre-eclampsia. This could be due to failure of estrogen synthesis owing to dysfunction of placenta in pre-eclamptic women ${ }^{10}$. In an observational case control study, a statistically significant relation was seen between TSH and antithyroid peroxidise (Anti-TPO) antibodies in women with pre-eclampsia ${ }^{11}$.

Proteinuria in pre-eclampsia leads to loss of albumin bound hormones in urine causing low serum total thyroxine $\left(\mathrm{TT}_{4}\right)$ and total triiodothyronine $\left(\mathrm{TT}_{3}\right)$ levels ${ }^{12}$. Upregulation of antiangiogenic biomarkers like sFlt1 and sEng (Soluble Endoglin) occurs in pre-eclampsia. These factors cause vasoconstriction, endothelial dysfunction and vascular damage. $^{13}$ Over expression of sFlt-1 brings about antiangiogenic state with low free placental growth factor and free vascular endothelial growth factor levels associated with subclinical hypothyroidism. ${ }^{9}$ The deiodination effect caused by D2-Thr92Ala genetic variant is associated with the severity of preeclampsia as well as biochemical hypothyroidism $^{14}$.

Despite myriad of studies, the effect of pregnancy induced hypertension on thyroid hormones still needs to be established. ${ }^{15}$ Factors that influence thyroid hormone levels like end stage renal disease, cardiac disease, liver disease, drug intake along with variations in reports of thyroid hormones based on the assay and reference ranges used make it even more difficult. ${ }^{16}$ Moreover increase in serum TSH levels may be accompanied with normal free thyroxine $\left(\mathrm{FT}_{4}\right)$ levels, condition called isolated hypothyroxinemia. Also while using serum TSH levels as a measure of maternal thyroid status, population and trimester specific reference ranges as in healthy Anti-TPO antibodies negative pregnant women with optimal iodine intake and without any prior thyroid ailment, provided by the particular institute or laboratory should be followed. However presently Serum TSH continues to be the parameter used for diagnosis and treatment of hypothyroidism, If internal or transferable pregnancy specific TSH reference ranges are not available ${ }^{17}$.

Hence, the following case control study was done to understand the relationship between pregnancy induced hypertension and maternal serum TSH levels.

\section{Materials and methods}

This case control study was carried out at KLEs Dr Prabhakar Kore Charitable Hospital which is a tertiary care centre at Belagavi, Karnataka. The sample size calculated for this case control study was 600. A total of 300 pregnant women were recruited in the case and control group each.
The duration of the study was a period of six months from June 2018 to December 2018. The study commenced after obtaining ethical clearance from the Institutional Ethics Committee.

Inclusion criteria: A total of 300 pregnant women with a diagnosis of pregnancy induced hypertension were included as cases. The diagnosis of pregnancy induced hypertension was made using current ACOG (The American College of Obstetricians and Gynaecologists) guidelines. Blood pressure $>140 / 90 \mathrm{~mm} \mathrm{Hg}$ on two occasions at least 4 hours apart after 20 weeks of gestation in a woman with previously normal blood pressure recordings was labelled as gestational hypertension, while high blood pressure with either new onset proteinuria ( $\geq 300 \mathrm{mg}$ in 24 hours, protein to creatinine ratio $\geq 0.3$ day or $1+$ urinary protein dipstick reading) or thrombocytopenia (platelet counts $<100,000 \mu \mathrm{L}$ ) or renal function impairement (creatinine $>1.1 \mathrm{mg} / \mathrm{dL}$ or 2-times rise in creatinine levels in absence of underlying renal disease) or impaired liver function (hepatic transaminase levels double that of normal) or pulmonary edema or cerebral or visual symptoms was labelled as preeclampsia. The cases were further divided into nonsevere and severe preeclampsia as per ACOG guidelines. Severe preeclampsia showed one of the following characteristics - 1) Systolic blood pressure $\geq 160 \mathrm{~mm} \mathrm{Hg}$ or diastolic blood pressure $\geq 110 \mathrm{~mm} \mathrm{Hg}$ recorded twice, 4 hours apart at bed rest; 2) thrombocytopenia (platelet counts $<100,000 \mu \mathrm{L}$ ); 3) impaired liver function or unexplained right upper quadrant epigastric pain not responding to medical treatment or hepatic transaminase levels double that of normal values; 4) progressive renal insufficiency ; 5) pulmonary edema; 6) new onset cerebral or visual disturbances.

In the above 300 cases recruited for the study, serum TSH was estimated at the time of diagnosis of pregnancy induced hypertension using enzyme linked immunosorbent assay (ELISA) method with venous blood sample. Current guidelines from the American Thyroid Association recommend use of population and trimester specific ranges for serum TSH during pregnancy. However due to the absence of consensus of any reference range for south Indian population an upper reference limit of $3.5 \mathrm{mIU} / \mathrm{mL}$ (as recommended by the ATA) was used to define hypothyroidism. ${ }^{17}$

A total of 300 normotensive pregnant during the study period were included in the control group after age and gestation matching. If any of the pregnant women developed hypertension any time during antenatal follow-up, they were excluded from the control group. 
The New Indian Journal of OBGYN. 2021 (January-June);8(2)

Exclusion criteria: Any pregnant women with history of chronic hypertension or prior history of thyroid dysfunction, thyroid surgery, usage of thyroid medication were not included in this study. Also pregnant women with a previous history of hepatic or renal disease or any other coexisting medical or surgical illness were not included in the study.

Statistical analysis: Study group (cases vs control) was considered as primary explanatory variable. Descriptive analysis was carried out by mean and standard deviation for quantitative variables, frequency and proportion for categorical variables. Categorical outcomes were compared between study groups using Chi square test /Fisher Exact test. P value $<0.05$ was considered statistically significant. IBM SPSS version 22 was used for statistical analysis.

\section{Results}

\begin{tabular}{|c|c|c|c|}
\hline Variables & $\begin{array}{l}\text { Control } \\
(n=300) \\
\text { Mean } \pm \text { SD }\end{array}$ & $\begin{array}{l}\text { Cases } \\
(n=300) \\
\text { Mean } \pm \text { SD }\end{array}$ & P value \\
\hline Age in years & $25.01 \pm 4.43$ & $24.68 \pm 3.82$ & 0.3242 \\
\hline Gestational age (wks) & $36.41 \pm 4.32$ & $37.07 \pm 3.64$ & 0.0424 \\
\hline $\mathrm{SBP}(\mathrm{mmHg})$ & $116.77 \pm 7.59$ & $142.79 \pm 16.55$ & $<0.0001$ \\
\hline DBP (mmHg) & $77.58 \pm 41.72$ & $92.71 \pm 10.05$ & $<0.0001$ \\
\hline S.TSH (mIU/ml) & $2.32 \pm 1.24$ & $2.81 \pm 2.08$ & 0.0006 \\
\hline S. Albumin (g/dL) & $3.30 \pm 0.38$ & $3.22 \pm 0.43$ & 0.0122 \\
\hline
\end{tabular}

SD - Standard deviation, S. TSH - Serum thyroid stimulating hormone, SBP - Systolic blood pressure, DBP - Diastolic blood pressure

Total 600 pregnant women were included in the study with 300 patients in case and control group each. Prior to analysis of the results of this study absence of confounding factors between the case and control groups was confirmed. The mean age of pregnant women and gestational age were

Table 2: Comparison of S. TSH and S. Albumin levels between
control and case groups $(\mathbf{N}=\mathbf{3 0 0})$

S. TSH - Serum thyroid stimulating hormone

tabulated to compare the control and Table 4: Comparison between gestational hypertension, non severe preeclampsia, severe preeclampsia case groups (table 1) with $\frac{\text { and control group }}{\text { Variables }}$

$(25.01 \pm 4.43)$ years and $(24.68 \pm 3.82)$ years respectively.

Mean gestationa S. Albumin $(\mathrm{g} / \mathrm{dL}) \quad 3.30 \pm 0.38$ control group was $(36.41 \pm 4.32)$
weeks while in the case group was Hypertension (37.07 \pm 3.64$)$ weeks. Owing to the $p$ value of $(0.3242)$ for age and $p$ value of (0.0424) for gestational age, differences between these two demographic features were not statistically significant. Systolic blood pressure recordings in

\begin{tabular}{|c|c|c|c|}
\hline Variables & $\begin{array}{l}\text { Control }(\mathbf{n}=300) \\
\text { Mean } \pm \text { SD }\end{array}$ & $\begin{array}{l}\text { Cases }(n=300) \\
\text { Mean } \pm \text { SD }\end{array}$ & P - value \\
\hline $\mathrm{Hb}(\mathrm{g} / \mathrm{dL})$ & $11.46 \pm 1.28$ & $11.52 \pm 1.69$ & 0.6323 \\
\hline PLTS (Lakh cells $/ \mathrm{mm}^{3}$ ) & $2.30 \pm 0.70$ & $2.19 \pm 0.64$ & 0.0421 \\
\hline B. Urea $(\mathrm{mg} / \mathrm{dL})$ & $16.89 \pm 6.76$ & $16.82 \pm 6.48$ & 0.9078 \\
\hline S. Creat (mg/dL) & $0.66 \pm 0.18$ & $0.65 \pm 0.19$ & 0.3120 \\
\hline $\mathrm{UA}(\mathrm{mg} / \mathrm{dL})$ & $4.11 \pm 0.95$ & $5.11 \pm 1.53$ & $<0.0001$ \\
\hline $\mathrm{TP}(\mathrm{g} / \mathrm{dL})$ & $6.25 \pm 0.51$ & $6.10 \pm 0.57$ & 0.0004 \\
\hline S. Alb (g/dL) & $3.30 \pm 0.38$ & $3.22 \pm 0.43$ & 0.0122 \\
\hline A: $\mathrm{G}$ & $1.08 \pm 0.28$ & $1.12 \pm 0.21$ & 0.0344 \\
\hline
\end{tabular}

SD - Standard deviation, Hb - Haemoglobin, PLTS - Platelets, B. Urea - Blood urea, S. Creat - Serum creatinine, UA - Serum uric acid, TP - Total protein, S. Alb - Serum albumin, A:G - Albumin : Globulin ratio.

the control group had a mean value of (116.77 7.59) $\mathrm{mm} \mathrm{Hg}$ while in the case group it was $(142.79 \pm 16.55) \mathrm{mm} \mathrm{Hg}$. While the diastolic blood pressure recorded in both groups had mean value of (77.58 \pm 41.72$) \mathrm{mm} \mathrm{Hg}$ for control group and mean value of $(92.71 \pm 10.05) \mathrm{mm} \mathrm{Hg}$ for case group. Both systolic and diastolic blood pressure recordings were significantly higher in the case group based on $\mathrm{p}$ value $(<0.0001)$. Mean TSH $(\mathrm{mIU} / \mathrm{L})$ of controls was $(2.32 \pm 1.24)$ and cases was $(2.81 \pm 2.08)$ with a highly statistically significant difference $(\mathrm{p}$ value $=0.0006)$. Comparison of mean serum albumin levels $(\mathrm{g} / \mathrm{dl})$ between controls $(3.30 \pm 0.38)$ and cases $(3.22 \pm 0.43)$ showed a significant difference ( $\mathrm{p}$ value $=0.0122$ ). Serum TSH levels and serum albumin of both groups were compared (table 2). 66 out of 300 cases $(22 \%)$ while 42 controls out of $300(14 \%)$ of had raised serum TSH levels $(>3.5 \mathrm{mIU} / \mathrm{ml})$. This difference was found to be statistically significant ( $\mathrm{p}$ value $=0.0108$ ) $234(78 \%)$ cases and $258(86 \%)$ controls had S.TSH within normal range. The serum albumin value was $>3.0 \mathrm{~g} / \mathrm{dl}$ in $267(89 \%)$ controls and in $236(78.67 \%)$ cases. While $33(11 \%)$ controls and $64(21.33 \%)$ cases had serum albumin levels lower than $3.0 \mathrm{~g} / \mathrm{dl}$. This difference was highly significant $(\mathrm{p}$ value $=0.0006)$. The patients in case and control group underwent laboratory testing for various blood markers and the results were compared (table 3). The mean haemoglobin $(\mathrm{g} / \mathrm{dL})$ for normotensive pregnant women 
Table 5 : Association between pregnancy induced hypertension and hypothyroidism

\begin{tabular}{lccc}
\hline Categories & $\begin{array}{c}\mathbf{0 . 1 3 3 . 5}(\mathbf{m I U} / \mathbf{m l}) \\
\text { (normal) } \\
\text { n (\%) }\end{array}$ & $\begin{array}{c}>\mathbf{3 . 5}(\mathbf{m I U} / \mathbf{m l}) \\
\text { (hypothyroidism) } \\
\text { n (\%) }\end{array}$ & OR (CI) \\
\hline Control & $258(86.00)$ & $42(14.00)$ & 1.87 \\
Severe PE & $79(76.70)$ & $24(23.30)$ & $(1.06-3.27)$ \\
\hline Control & $258(86.00)$ & $42(14.00)$ & 1.41 \\
Non severe PE & $83(81.37)$ & $19(18.63)$ & $(0.78-2.55)$ \\
\hline Control & $258(86.00)$ & $42(14.00)$ & 1.24 \\
Gest HTN & $79(83.16)$ & $16(16.84)$ & $(0.66-2.33)$ \\
\hline
\end{tabular}

PE - Preeclampsia, HTN - Hypertension, OR - Odds ratio, CI - Confidence interval

mean values was statistically insignificant $(\mathrm{p}$ value $=$ 0.6323 ). The mean platelet count (lakh cells $/ \mathrm{mm}^{3}$ ) was $(2.30 \pm 0.70)$ for controls and $(2.19 \pm 0.64)$ for cases with a statistically significant difference $(\mathrm{p}$ value $=0.0421)$. Mean values for blood urea $(\mathrm{mg} / \mathrm{dL})$ were $(16.89 \pm 6.76)$ in controls and (16.82 \pm 6.48$)$ in cases, the difference being statistically insignificant $(\mathrm{p}$ value $=0.9078)$. For serum creatinine levels Table 6: Correlation between serum albumin and S. TSH for both case and control groups taken together

\begin{tabular}{ll}
\hline Correlation coefficient ( $r)$ & $\mathbf{P}$ - value \\
\hline
\end{tabular}

$-0.05320 .1931$

S. TSH - Serum thyroid stimulating hormone

$(\mathrm{mg} / \mathrm{dL})$, mean in controls was $(0.66 \pm 0.18)$ and in cases was $(0.65 \pm 0.19)$ with statistically insignificant difference ( $p$ value $=0.3120)$. Serum uric acid was measured with mean values $(4.11 \pm 0.95)$ controls and $(5.11 \pm 1.53)$ cases. The difference was statistically highly significant (p value $<0.0001$ ). Serum

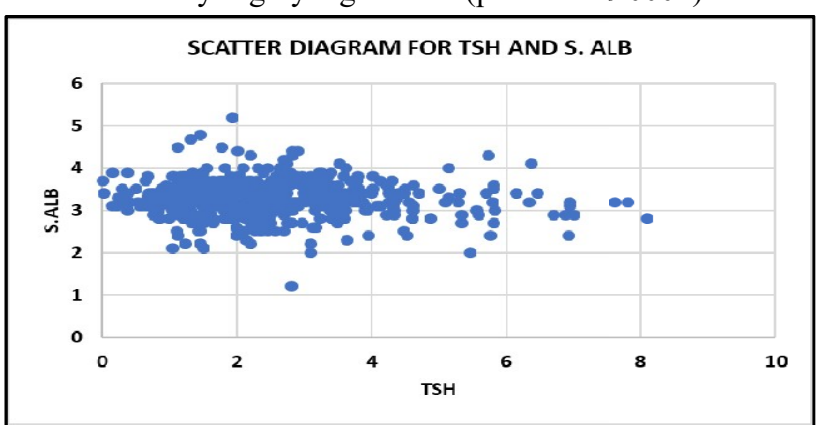

Graph 1: Negative correlation between thyroid stimulating hormone and serum albumin

total protein $(\mathrm{g} / \mathrm{dL})$ mean values were $(6.25 \pm 0.51)$ controls, $(6.10 \pm 0.57)$ cases with a highly significant difference ( $p$ value $=0.0004)$. Mean Serum albumin $(\mathrm{g} / \mathrm{dL})$ was (3.30 \pm 0.38$)$ among controls and (3.22 \pm 0.43$)$ among cases with significant difference $(\mathrm{p}$ value $=0.0122$ ). Serum albumin and globulin ratio was also done with mean values $(1.08 \pm 0.28)$ for controls and $(1.12 \pm 0.21)$ for cases with a statistically significant difference ( $\mathrm{p}$ value $=0.0344$ )

The case group was further divided into gestational hypertension, non severe preeclampsia and severe preeclampsia. The means of variables of these subgroups were compared with each other as well as those of the control group (table 4). The mean age (in years) of the cases with gestational hypertension was $(24.95 \pm 3.60)$, non severe preeclampsia was $(25.01 \pm 4.43)$ and severe preeclampsia was (25.25 \pm 4.24$)$ while that of control group was $(25.01 \pm 4.43)$. Since this difference was statistically significant ( $\mathrm{p}$ value $=$ 0.0593 ), all the groups were comparable. The mean value of S.TSH $(\mathrm{mIU} / \mathrm{ml})$ among gestational hypertension cases was $(2.42 \pm 1.33)$, non severe preeclampsia was $(2.66 \pm 1.52)$ and severe preeclampsia was $(3.31 \pm 2.89)$ while that of control group was (2.32 \pm 1.24$)$. This difference was statistically highly significant ( $\mathrm{p}$ value $<0.0001$ ). For serum albumin $(\mathrm{gm} / \mathrm{dL})$, the mean value was $(3.27 \pm 0.41)$ in gestational hypertension cases $(3.27 \pm 0.38)$ in non severe preeclampsia cases was $(3.12 \pm 0.47)$ in severe preeclampsia cases while that in control group was $(3.30 \pm 0.38)$. The difference in these mean values was very significant $(\mathrm{p}$ value $=0.0013$ ).

As seen in (table 5), 24(23.30\%) cases with severe preeclampsia, $19(18.63 \%)$ with non severe preeclampsia and $16(16.84 \%)$ cases with gestational hypertension had S TSH $>3.5 \mathrm{mIU} / \mathrm{ml}$. The association between preeclampsia and hypothyroidism was seen by odds ratio of $1.87(\mathrm{CI}=1.06$ $3.27)$ for patients with severe preeclampsia, $1.41(\mathrm{CI}=0.78$ 2.55) for patients with non severe preeclampsia and 1.24 (CI $=0.66-2.33$ ) for patients with gestational hypertension in comparison to the normotensive patients.

For the entire study population (both control and case group), the coefficient correlation was (-0.0532) between serum albumin and serum TSH which showed a negative correlation without any statistical significance (table 6, graph 1).

Fetal outcome was compared in terms of birth weight $(\mathrm{kg})$ between the control and case group with mean values $(2.71 \pm 0.49)$ for controls and $(2.37 \pm 0.76)$ for cases with a highly statistically significant difference ( $\mathrm{p}$ value $<0.0001$ ).

\section{Discussion}

With the case and control group having comparable age and gestational age, hypothyroidism in hypertensive pregnant women was found to be significantly very high with $22 \%$ of cases with serum $\mathrm{TSH}>3.5 \mathrm{mIU} / \mathrm{ml}$ than in normotensive pregnant women with only $14 \%$ patients with hypothyroidism. Earlier studies have also shown higher number of preeclamptic patients with hypothyroidism. ${ }^{10,19-21}$ Serum albumin levels were significantly lower in the hypertensive group with $21.33 \%$ cases as compared to normotensive group with $11 \%$ patients having serum albumin $<3.0 \mathrm{~g} / \mathrm{dL}{ }^{22,23} \mathrm{We}$ also found that the decrease in 
The New Indian Journal of OBGYN. 2021 (January-June);8(2)

serum albumin correlated with the severity of pregnancy induced hypertension. ${ }^{23,24}$

It was found that the mean serum TSH level increased as the pathology of pregnancy induced hypertension progressed along the spectrum of gestational hypertension to non severe to severe preeclampsia which showed a stronger association of hypothyroidism with severity of pregnancy induced hypertension based on odds ratio. ${ }^{12,19,23}$

The negative correlation between the serum TSH and serum albumin levels showed both values were independent of each other. There has been no correlation found at all between the two values in certain studies before. Some of the earlier studies did not find any significant association between hypertension and serum TSH levels. $^{25,26}$

Other blood parameters were also compared between the case and control groups. Haemoglobin, blood urea, serum creatinine values did not vary significantly between the two groups. However serum uric acid levels were found significantly higher among the hypertensives as compared to the normotensives, while platelets, total proteins and serum albumin were significantly lower in hypertensive group. The albumin to globulin ratio was significantly higher in the hypertensive group.

The effect of hypertension on birth weight of babies was seen as a fetal outcome with significantly lower birth weights in hypertensive patients as compared to normotensive patients.

\section{Conclusion}

The purpose of the above study was to find the association between biochemical hypothyroidism and preeclampsia in pregnant women. The results of the study suggest there may be a higher chance of hypothyroidism in hypertensive patients as the spectrum of severity of hypertension advances. A major drawback of this study was the inability to use serum T4 and T3 in our analysis. This was primarily due to financial constraints of patients admitted at our charitable hospital. Other factors were absence of population and assay manufacturer specific reference ranges for interpretation of the values. The need for trimester specific reference range of thyroid hormone levels for South Indian population also represents a prospective area of further research. Identification of one may help in anticipation of existence of the other condition which may further prevent maternal mortality and morbidity along with adverse fetal outcomes.

\section{Conflict of interest: None. Disclaimer: Nil.}

\section{References}

1. Sahay RK, Nagesh VS. Hypothyroidism in pregnancy. Indian J Endocrinol Metab. 2012; 16(3): 364-70.

2. LeBeau SO, Mandel SJ. Thyroid disorders during pregnancy. Endocrinology and Metabolism Clinics of North America. 2006 Mar; 35(1): 117-36.

3. Mandel SJ, Spencer CA, Hollowell JG. Are detection and treatment of thyroid insufficiency in pregnancy feasible? Thyroid. 2005; 15(1): 44-53.

4. Klein RZ, Haddow JE, Faix JD, et al. Prevalence of thyroid deficiency in pregnant women. Clin Endocrinol (Oxf). 1991; 35(1): 41-6.

5. Mukhopadhyay A, Pati S, Mukherjee S, Das N, Mukhopadhyay P, Saumandal B. Autoimmune thyroid disorders and pregnancy outcome: a prospective observational study. Thyroid Research and Practice. 2007; 4(1): 50-2.

6. Nambiar V, Jagtap VS, Sarathi V, Lila AR, Kamalanathan S, Bandgar TR, et al. Prevalence and impact of thyroid disorders on maternal outcome in Asian-Indian pregnant women. J Thyroid Res. 2011; 2011: 429097.

7. Dhanwal DK, Bajaj S, Rajput R, Subramaniam K, Chowdhury S, Bhandari R, et al. Prevalence of hypothyroidism in pregnancy: An epidemiological study from 11 cities in 9 states of India. Indian $\mathrm{J}$ Endocr Metab. 2016; 20: 387-90.

8. Dhanwal DK, Prasad S, Agarwal AK, Dixit V, Banerjee AK. High prevalence of subclinical hypothyroidism during first trimester of pregnancy in North India. Indian J Endocrinol Metab. 2013; 17: 281-4.

9. Levine RJ, Vatten LJ, Horowitz GL, et al. Preeclampsia, soluble fms-like tyrosine kinase 1, and the risk of reduced thyroid function: nested case-control and population based study. BMJ. 2009; 339: b4336.

10. Kaye E, Sahin Y, Ozkececi Z, Pasaoglu H. Relation between birth weight and thyroid function in preeclampsia-eclampsia. Gynecol Obstet invest. 1994; 37: 30-3.

11. Harshvardhan L, Dariya SS, Sharma A, Verma L. Study of Association of Thyroid Hormone in Pre-Eclampsia and Normal Pregnancy. J Assoc Physicians India. 2017; 65(11): 44-6.

12. Lao TT, Chin RK, Swaminathan R, Lam YM. Maternal thyroid hormones and outcome of pre-eclamptic pregnancies. Br J Obstet Gynaecol. 1990; 97: 71-4.

13. Maynard SE, Karumanchi SA. Angiogenic factors and preeclampsia. Semin Nephrol. 2011; 31(1): 33-46. 
The New Indian Journal of OBGYN. 2021 (January-June);8(2)

14. Procopciuc LM, Caracostea G, Hazi G, Nemeti G, Stamatian F. D2-Thr92Ala, thyroid hormone levels and biochemical hypothyroidism in preeclampsia. Gynecol Endocrinol. 2017; 33(2):136-40.

15. Gui J, Xu W, Zhang J. Association between thyroid dysfunction and perinatal outcomes in women with gestational hypertension: a retrospective study. BMC Pregnancy Childbirth. 2020; 20(1): 119.

16. Welsh KJ, Soldin SJ. Diagnosis of endocrine disease: How reliable are free thyroid and total T3 hormone assays? Eur J Endocrinol. 2016; 175(6): R255-R263.

17. Alexander EK, Pearce EN, Brent GA, et al. 2017 Guidelines of the American Thyroid Association for the Diagnosis and Management of Thyroid Disease During Pregnancy and the Postpartum. Thyroid. 2017; 27(3): 315-89.

18. American College of Obstetricians and Gynecologists; Task Force on Hypertension in Pregnancy. Hypertension in pregnancy. Report of the American College of Obstetricians and Gynecologists' Task Force on Hypertension in Pregnancy. Obstet Gynecol. 2013; 122(5):1122-31.

19. Muraleedharan N, Janardhanan JS. Thyroid hormone status in preeclampsia patients: A case-control study. Muller J Med Sci Res. 2017; 8: 68-73.

20. Kumar A, Ghosh BK, Murthy NS. Maternal thyroid hormonal status in preeclampsia. Indian $\mathrm{J}$ Med Sci. 2005; 59: 57-63.

21. Tadas SA, Tadas AK. Thyroid hormone alteration in women with pre-eclampsia. Int J Res Med Sci. 2016; 4: 4520-3.
22. Chowdhary S, Nazeer M, Bhat AN. Correlation of serum albumin, $A ; G$ ration and thyroid function tests in normal pregnant women and preeclamptic women. International Journal Of Scientific Research. 2018 Aug 31; 7(8): 41-3.

23. Sardana D, Nanda S, Kharb S. Thyroid hormones in pregnancy and preeclampsia. J Turk Ger Gynecol Assoc. 2009; 10:168-71.

24. Margarson MP, Soni N. Serum albumin: Touchstone or totem? Anaesthesia. 1998; 53: 789-803.

25. Qublan HS, Al-Kaisi IJ, Hindawi IM, Hiasat MS, Awamleh I, Hamaideh AH, et al. Severe pre-eclampsia and maternal thyroid function. J Obstet Gynaecol. 2003; 23: 244-6.

26. Raoofi Z, Jalilian A, Shabani Zanjani M, Parvar SP, Parvar SP. Comparison of thyroid hormone levels between normal and preeclamptic pregnancies. Med J Islam Repub Iran. 2014; 28:1

\footnotetext{
Mahadevi Savanur ${ }^{1}$, Anubha Kataria ${ }^{2}$, Gauri Prabhu ${ }^{3}$, Nitin Sutariya ${ }^{4}$

${ }^{1}$ Assistant Professor, Department of Obstetrics and Gynaecology, JNMC, KAHER, Belgavi, Karnataka, India;

${ }^{2}$ Junior Resident (Post Graduate Student), Department of Obstetrics and Gynaecology, The Oxford Medical College Hospital and Research Centre, Bengalore, India; ${ }^{3}$ Assistant Professor, Department of Obstetrics and Gynaecology, JNMC, KAHER, Belgavi, Karnataka, India; ${ }^{4}$ Junior Resident, Department of Obstetrics and Gynaecology, GMERD Medical college, Valsad, Gujarat, India.
} 